\title{
Quality criteria for conceptual technology integration models in education: bridging research and practice
}

\author{
Jo Tondeur ${ }^{1}$ (D) Dominik Petko $^{2} \cdot$ Rhonda Christensen $^{3} \cdot$ Kerstin Drossel $^{4}$. \\ Louise Starkey ${ }^{5}$. Gerald Knezek ${ }^{3}$. Denise A. Schmidt-Crawford ${ }^{6}$
}

Accepted: 18 November 2020

(c) Association for Educational Communications and Technology 2021

\begin{abstract}
In order to effectively use technology in education, appropriate conceptual understandings are needed to guide the integration process. Today, there is a wide range of conceptual models that are developed and used in research and/or practice focusing on educational technology integration. Conceptual models are of relevance as they can bridge theory with practical applications. Today, there are a wide range of conceptual models are developed and used in research and/or practice focusing on educational technology integration. These models can be seen as simplified versions of theories for practical application or as condensed wisdoms of practice that need to be further investigated theoretically and empirically. However, there is insufficient agreement on the dimensions and criteria used to judge the quality of conceptual models in educational technology. Therefore, the main goals of this article are to: (1) develop criteria to assess the quality and scope of conceptual models and (2) identify and compare exemplary models for technology integration in educational settings along with these quality criteria. The resulting five criteria from this investigation provide the means to effectively evaluate the quality and scope of conceptual models focused on technology integration while providing additional insight into applying these models in research and practice.
\end{abstract}

Keywords Conceptual models · Technology integration · Quality criteria · Education · Visual models

Jo Tondeur

Jo.Tondeur@vub.be

1 Multidisciplinary Institute of Teacher Education, Vrije Universiteit Brussel, B1050 Brussels, Belgium

2 University of Zurich, Zurich, Switzerland

3 University of North Texas, Denton, USA

4 Paderborn University, Paderborn, Germany

5 Victoria University of Wellington, Wellington, New Zealand

6 Iowa State University, Ames, USA 


\section{Introduction}

In order to use technology effectively in education, appropriate conceptual understandings are needed to guide the integration process. Currently, there is a range of conceptual models that have been developed and used in research and practice (Niederhauser and Lindstrom 2018; Sosa and Manzuoli 2019). Some models have stimulated international research initiatives such as the TPACK (Technological Pedagogical Content Knowledge) Model (Koehler and Mishra 2009; Mishra and Koehler 2006); the "Will-Skill-Tool" or "Will-Skill-Tool-Pedagogy" Model (Christensen and Knezek 2001; Knezek and Christensen 2016); or pedagogical adaptations of generic Technology Acceptance Models (Davis 1989; Venkatesh et al. 2003). Other models have been applied to practice such as the Substitution-Augmentation-Modification-Redefinition Model (SAMR; Puentedura 2006, 2012), the Technology Integration Matrix (TIM; Welsh et al. 2011), the Technology Integration Planning Model (TIP; Roblyer and Doering 2013) or the Four in Balance Model (Kennisnet 2014). Early models focused on the removal of barriers (anxieties, fears, access), while more recent ones have featured the development of knowledge and skills, the acknowledgement of pedagogical practice or the combining of factors on different levels of the educational system within a multilevel perspective (Petko et al. 2018). These ideas are situated in the work resulting from the authors' participation in a thematic working group while attending the 2019 International Summit on ICT in Education (EDUSummIT). The group's task was to advance models and theories of technology integration which intersects well with this special issue's theme of Learner and Learning Contexts: International Perspectives on New Alignments for the Digital Age and to examine how technology integration models align with specific dimensions and criteria in order to determine the quality and scope of using such diverse models in teaching and learning contexts.

Clearly, some diversity in models can be valuable in order to focus on different aspects and inform technology integration in education, but too much diversity may be counterproductive as it hinders cumulative knowledge building and fails to provide coherent guidelines for practitioners. Based on these observations, there is insufficient agreement on dimensions and criteria to judge the quality of conceptual models in the field of educational technology use. Thus, the main goals of this article are to (1) develop criteria to assess the purpose, the quality and the scope of different conceptual models and (2) identify and compare exemplary models for technology integration in educational settings along these criteria.

\section{Conceptual models: positioning and definition}

To identify the specific properties of conceptual models, it is necessary to compare them to theories or theoretical, empirical and mental models (Frigg and Hartmann 2018; Grønfeldt Winther 2015). In philosophy of science, theories are typically understood as coherent and valid sets of statements describing specific phenomena in an abstract, logical and generalizable way. Theories identify core factors and describe relationships between these factors either by means of cause-effect statements or by more complex logical or mathematical rules. Theories can be condensed into theoretical models with variable-based sets of rules precise enough to be applied to real-world evidence. In empirical sciences, theoretical models are used to frame and state hypotheses that are tested with empirical models. 
In quantitative methodology, empirical models are used to describe patterns in numerical data, calculate effect sizes, probability coefficients and model fit. In qualitative methodology, empirical models are discovered and tested through the generation and application of analytical categories that are applied to non-numerical data, systematic case-based comparisons and the creation of cross-case typologies.

Conceptual models are closely related to theoretical and empirical models but they can be viewed as something more pragmatic, especially in the social sciences. Conceptual models are typically situated in practical considerations rather than solely a theoretical point of view. Here, conceptual models can represent a social phenomenon or process that may lack the certainty and material focus represented in scientific models of exact or natural sciences (Svetlova and Dirksen 2014). Conceptual models can thus draw on a bricolage of scientific, social science and professional practice epistemologies and often aim to connect theory and professional practice. Conceptual models also differ from scientific models with regard to their purpose. In psychology, conceptual models are seen as "words and/or diagrams that are intended to help learners build mental models" (Mayer 1989). They are assumed to be beneficial for the formation of mental models, which guide everyday behavior and reflection (Johnson-Laird 2013; Moreira 2000). Thus, conceptual models are expected to provide a bridge from theory to practical application (Von Glasersfeld and Steffe 1991). Furthermore, they can be simplified versions of theories as well as practical working assumptions for further empirical and theoretical investigations.

As conceptual models can be considered as an intermediate between generalizable scientific models (i.e. theoretical and empirical models) and individual mental models, the definition of conceptual models can be initiated from both sides of this spectrum. Some conceptual models emerge from scientific research, where findings are condensed into simplified conceptual models in order to facilitate practical application. Examples from research on educational technology include the aforementioned Technological Pedagogical Content Knowledge (TPACK) Framework, the Will-Skill-Tool-Pedagogy Model, or the Synthesis of Qualitative Data (SQD) Model. Other conceptual models emerge from practice, where successful innovators try to summarize their experiences in a more structured and generic way, which may trigger additional research. Prominent examples include the Substitution-Augmentation-Modification-Redefinition (SAMR) Model, the Technology Integration Matrix (TIM) or the Four in Balance Model. When judging these models exclusively along quality criteria for theoretical models, the conceptual models that were developed in a scientific context will seem more valid. However, when considering the purpose of conceptual models, it becomes apparent that this might not be adequate. Therefore, specific quality criteria for conceptual models need to be developed and applied.

\section{Towards quality criteria for conceptual models}

There are no clear quality criteria for conceptual models of educational technology integration. This might be one reason why practitioners seem to judge models by their visual appeal or simplicity rather than their scientific validity (Kimmons and Hall 2018). The development of quality criteria could help address this issue by providing a framework to evaluate conceptual models more thoroughly. Therefore, the specific properties of different kinds of models need to be clarified.

Quality criteria for scientific models are closely related to issues of measurement and analysis, in particular validity and reliability, among others (e.g. Bryman 2016; Cohen 
et al. 2018). With a wider and overarching perspective, Kuhn (1977) proposed the following quality criteria for scientific theories and models:

- Accuracy (i.e. the theory is supported by empirical findings and the corresponding empirical model explains a large part of the variance in the data),

- Consistency (i.e. the theory provides a logical chain of reasoning, also in combination with other proven theories),

- Scope (i.e. the theory is applicable to a wide range of phenomena with a high degree of generalizability),

- Simplicity (i.e. the theory reduces complexity of an otherwise confusing interplay of objects and their properties),

- Fruitfulness (i.e. the theory should disclose new phenomena or previously unnoted relationships).

An important question is whether the quality criteria for scientific models are applicable to conceptual models. Although there have been attempts to use purely scientific quality criteria to assess conceptual technology integration models such as TPACK (see Archambault and Barnett 2010; Kimmons 2015), these assessments seem to miss the specific practice-oriented properties of conceptual models. To provide a broader and more adequate perspective, the quality criteria proposed by Kuhn need to be expanded to be applicable to conceptual models and their specific purpose. For example, Norman (1983) proposes three quality criteria for conceptual models which are geared towards their potential to stimulate learning and innovation of practice: "learnability", "functionality" and "usability". In addition, conceptual models are supposed to facilitate the integration in individual mental models, which are considered to have quality criteria that are rather personal: coherence, purpose, personal relevance, integration with other knowledge, real-world fidelity, imagery and metaphors, complexity, applicability and inferential/implicational ability (Jonassen 1995). While the criteria of Kuhn could be expanded with these additional aspects, they can also be integrated in the existing criteria. This provides a simpler and more coherent framework to judge the specific quality of conceptual models. Table 1 proposes an overview along with an adaptation of the criteria proposed by Kuhn (1977) for conceptual and mental models.

The adjustments made to the criteria for conceptual models can be explained as follows:

- Regarding the criterion of accuracy, empirical validation is equally essential for conceptual models as for scientific models, however, conceptual models need to be supplemented with practical validation in context. A good model of educational technology integration should be able to be applied in context before validation, provided known limitations are explicit and transparent.

- The criterion of consistency needs to be expanded in relation to other conceptual models and identified epistemologies. For example, a good conceptual model of educational technology integration is clearly conceptualized, focuses on important aspects and provides coherent statements on the interplay of factors. It relates to other models, frameworks and theories and demonstrates validity for both researchers and practitioners.

- The criterion of scope needs to be conceptualized in a slightly different manner. Instead of aiming for the highest levels of generalizability, conceptual models need to provide information that facilitates contextual application which takes account of the social aspects of educational technology integration. A good model of educational technology integration should bridge theory and practice and specify the context or contexts 


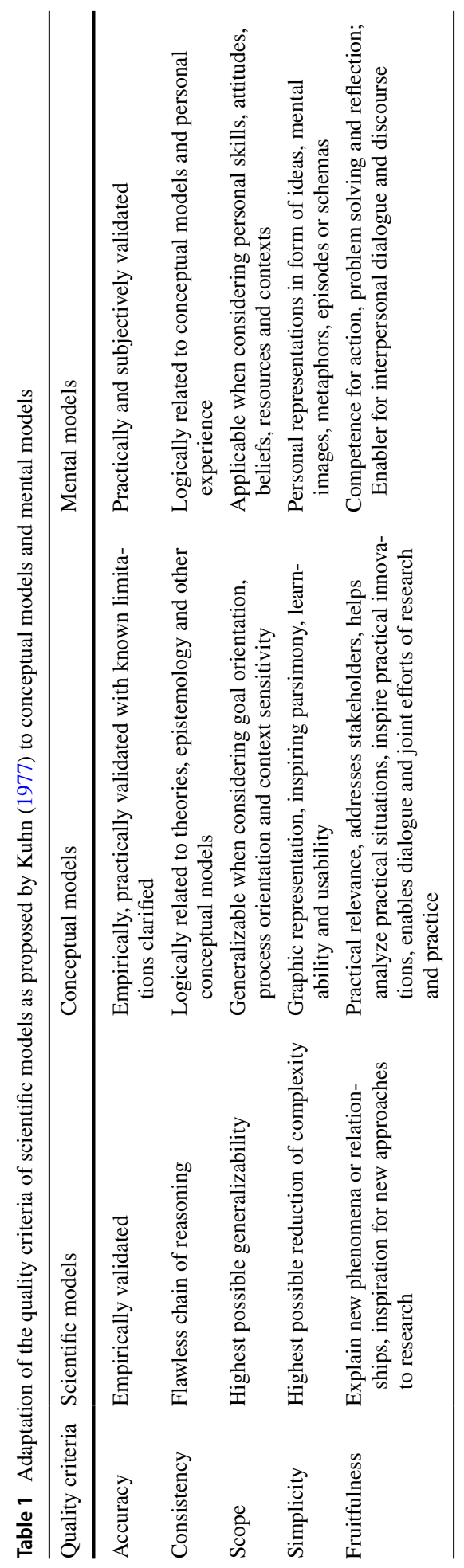


relevant to its application. Specified contexts could include; specific/multiple aggregation levels of the educational system, grade or educational levels, the involvement of specific stakeholders, contextual conditions, or the dynamic processes and mechanisms for technology integration. Two dimensions stand out in this regard: (1) the question of whether a model focuses on either teacher-related or student-related aspects and (2) whether it includes micro (i.e. classroom-level), meso (i.e. teacher- or student-level), or macro level (i.e. school- or system-level) aspects. These dimensions are very common in general research on educational effectiveness (e.g. Creemers 1994; Scheerens 2016) as well as in the literature on technology integration and its barriers (Ertmer 1999; Pelgrum and Plomp 1993; Rosenberg and Koehler 2015; Tsai and Chai 2012). Based on these considerations, the authors have developed the Stage for Technology Integration Models (STIM) framework to consider the scope of educational technology integration models (see Fig. 1).

- With regard to simplicity, models should be neither too simple nor too complex but parsimonious in the following sense: "A stimulus that is very simple relative to the knowledge and experience of the viewer will soon become boring: such an obvious pattern will soon exhaust its interest and usefulness. If the stimulus is very complex relative to the knowledge and experience of the viewer no pattern will be recognized in it and it will not be applied. Only if the viewer can continue over some time, to detect new patterns in the stimulus, or to elaborate the pattern that has been detected, will

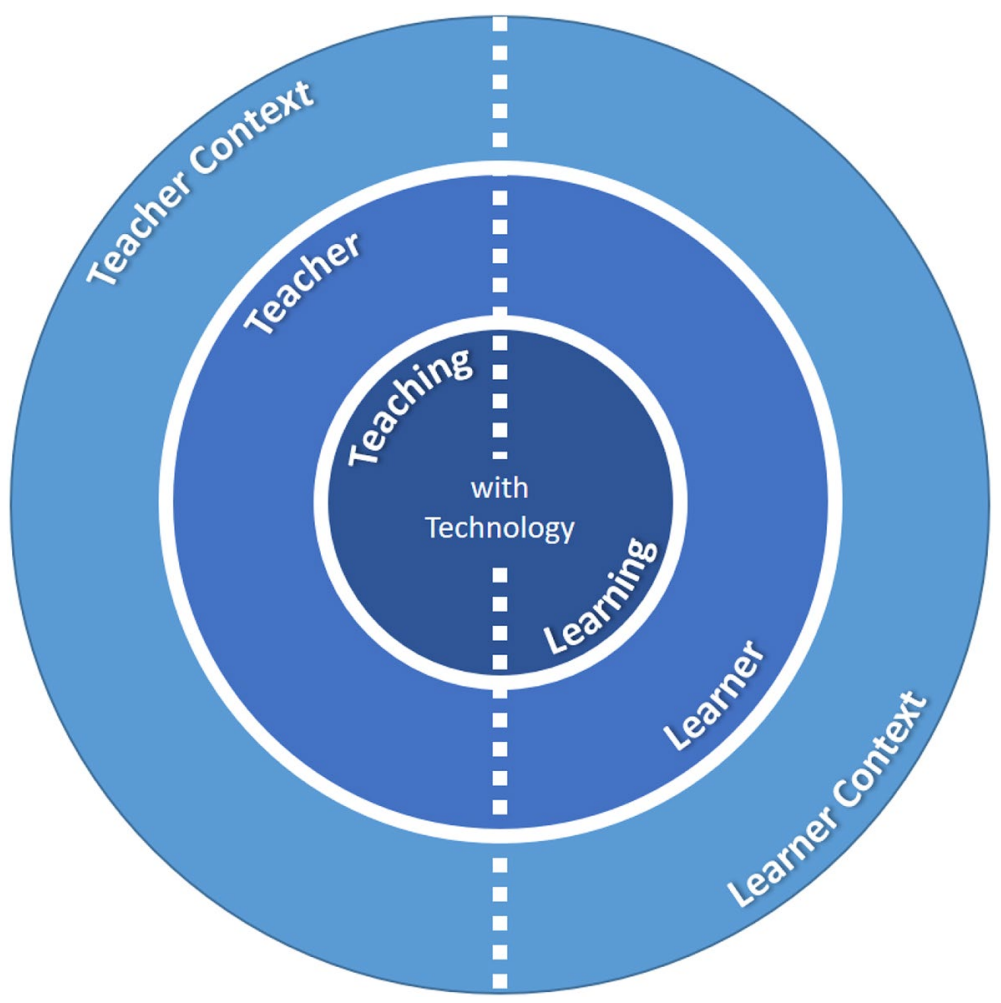

Fig. 1 Stage for Technology Integration Models (STIM) framework 
his or her attention continue to focus on it. What is moderately complex relative to the viewer is interesting and beautiful because it can be perceived in terms of parsimonious patterns that can be extracted with reasonable effort" (Simon 2001, p. 3). Therefore, conceptual models are typically depicted visually which make them likely to be communicated and applied in practice. A good conceptual model of educational technology integration catches attention and reduces complexity, and is easily learned and remembered. For example, it may provide a clear Gestalt/ontology.

- The criterion of fruitfulness is focused on the consequences of applying conceptual models to practical situations. Fruitful conceptual models inspire new ways of understanding the affordances and constraints of practice and spark innovation. At the same time, these innovations are relevant for research as well. As conceptual models are informed by research as much as they are grounded in practice, they provide opportunities for a close collaboration between these two domains. Conceptual models offer a tangible middle ground—which has also been called a "third space" (Bhabha 1994)— for dialogue between the cultures of science and practice. In particular, conceptual models can provide a pivotal point for design-based research, participatory research and practitioner research that helps to bridge the gap between theory and more practical types of knowledge (Heikkinen et al. 2016).

In sum, there are numerous recommendations regarding quality criteria for theoretical and empirical models but few that also include criteria specific for conceptual models. Table 1 provides a list of criteria for conceptual models to help bridge the gap between scientific models and mental models.

\section{Applying the quality criteria to different conceptual models}

In recent overviews of technology integration models, numerous models are listed and described (Niederhauser and Lindstrom 2018; Phillips 2015; Sosa and Manzuoli 2019). However, there are few attempts to compare existing models along relevant dimensions or to combine them into an overarching model. To provide a more coherent and structured overview, it is necessary to specify what technology integration means. In the past, technology is integrated when it is used in a seamless manner to support and extend curriculum objectives and to engage students in meaningful learning (Earle 2002). More recently, this understanding has been expanded to meet the affordances of twenty-first century education (Collins and Halverson 2010; Voogt et al. 2013). Instead of understanding technology integration as an effective add-on to existing teaching practices, technology integration requires more fundamental adaptations to the curriculum and the culture of teaching and learning. Although for decades scholars such as Hattie (2009) have reaffirmed the early work of Kulik and Kulik (1991) that technology can be effective in promoting learning, recently Schneider and Prekel (2017) summarized 38 meta-analysis studies to conclude that technology affordances still lag behind five other categories of instructional practices in promoting higher education achievement. This echoes the conclusions of Tondeur et al. (2008) that typical technology affordances do not exploit the full potential of IT, rather they particularly use the basic features of technology.

As technology and pedagogy evolve in the digital age, teachers face many challenges while integrating the available technology into classroom practices. This integration is complex and multifaceted (Ertmer et al. 2012; Inan and Lowther 2010; Knezek and 
Christensen 2016). It is influenced by a range of social, personal, contextual and technological factors which can change over time. As a result, this leads to a variety of conceptual models with differing focus and scope which draw on diverse theoretical schools of thought. These models may depict similar phenomena with dissimilar terminology and when the models are applied to research the conclusions drawn could vary. To advance technology integration in education, it is not only paramount to develop and recognize high quality conceptual models that can be applied to future research and practice but also to provide a common framework to compare and combine different models.

To test the applicability of our criteria and the framework that were described earlier in this article, we chose three technology integration models that were represented by scholars included in our EDUsummIT working group. In addition, the set of exemplary models represent an interesting spectrum of variations that derive from results of empirical research, systematic reviews and wisdom of practice.

\section{Will, skill, tool and pedagogy model}

The Will, Skill, Tool and Pedagogy (WSTP) Model of technology integration is an exemplar of a conceptual model that has been developed in the context of empirical research (Knezek and Christensen 2016). It features four interdependent constructs that influence the integration of technology in the classroom (see Fig. 2). All four constructs are assumed to be important contributors to the integration of technology. For example,

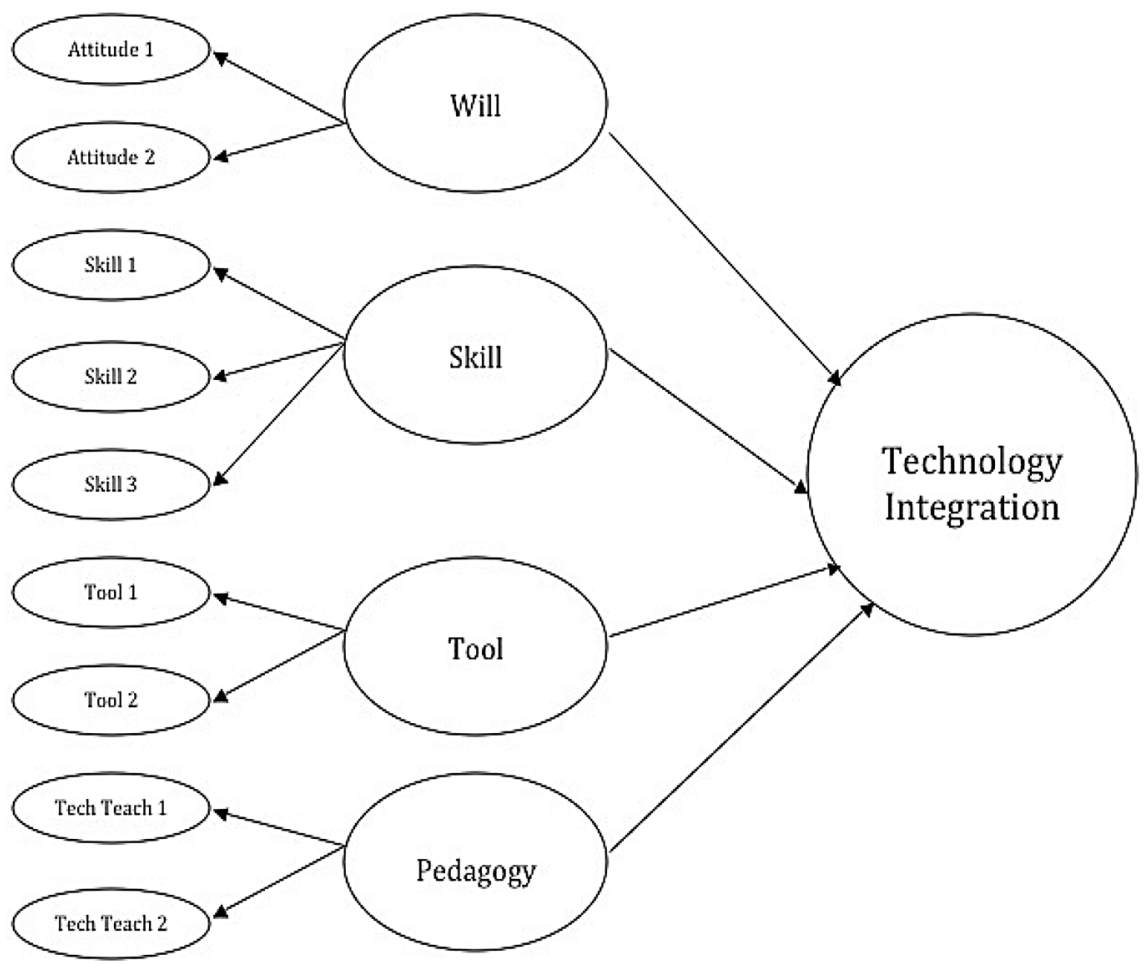

Fig. 2 Will, skill, tool, pedagogy model of technology integration 
educators who have received training and practice on technology and are willing to use it with their students-yet have no access to technology in their schools-are clearly not able to integrate technology into learning. Thus the area named Tool is related to availability, accessibility and extent of technology use. Many schools provide a great deal of hardware and software (tools), yet provide little or no professional development for teachers. For these types of school environments, purchases often go unused. Skill is the ability to use and experience technology (Coughlin and Lemke 1999), as well as the self-perceived confidence (self-efficacy) and readiness to use technology. Skill proficiency is most commonly established through professional development. Acceptance of the value and worth of technology, along with the will to use it to enhance student learning, is another critical component of the model. Will is conceptually defined as a positive attitude toward the use of technology in instruction. Pedagogy is the fourth critical component of the model as it affects how technology is used in the teaching process. Technology Integration is the self-perceived level of adoption of technology for educational purposes. Each of the constructs can be assessed by multiple measures.

In applying the suggested quality criteria, the WSTP Model meets the criteria in the following ways. The accuracy of the model was validated with structural equation modeling (Knezek et al. 2000) as well as construct validation (Knezek and Christensen 2016). The validated measures that contributed to the model were found to predict technology integration in the classroom (Knezek and Christensen 2016). However, the criterion of accuracy also includes the need to be practically validated in addition to empirical validation. Here, the accuracy of the model across different contexts is less clear. For example, it is unclear how the model is applicable in high-tech environments where the importance of the tool factors is likely to be of minor importance. There are some known case studies where the WSTP model was successfully used to analyze and inform practice (Agyei and Voogt, 2011; Farjon et al. 2019; Petko 2012). In most of these studies, especially in the context of teacher professional development, the model addresses the issue that there should not be an overemphasis on a single aspect of the model without addressing the others.

With regard to the quality criteria of consistency, the WSTP Model is believed to be consistent with other models and frameworks, as well as theories. WSTP as a conceptual model is consistent with other models such as TPACK, especially regarding the emphasis on the interdependence of technology integration on factors such as teacher, student, technology access and skill. In addition, the measures used to contribute to the WSTP model were based on underlying theoretical models such as Bandura's (1977) self-efficacy and Rogers' (1995) Diffusion of Innovation and the Concerns-based Adoption Model (CBAM: Hall 1974). However, it is unclear how this model relates to more recent and popular conceptual models like the SAMR or the TIM models, where technology integration is conceptualized as a matter of educational innovation rather than getting comfortable in the adoption process in CBAM.

With regard to scope, it needs to be noted that the WSTP Model focuses mainly on the teacher side of the technology integration equation. In other respects, the WSTP model has been found to be broad in scope. For example, it can be used across grade levels and has been used in multiple studies in other countries (Agyei and Voogt 2011; Morales 2006; Tondeur et al. 2012; Petko 2012). The WSTP Model is flexible in that it allows different measures to be used as inputs for the four constructs in different locations, but that also may cause the loss of consistency in attempting to re-validate the model. The measures used for each construct can vary as long as they are reliable measures. However, it was designed for formal learning environments and has not been tested in other contexts. 
The WSTP Model also encompasses simplicity as it contains only four components but clearly has multiple measures that contribute to the quality of these constructs. However, while it is simple to talk about the four components, it is more complex to obtain measurements for the model as a whole and it cannot really be tested with one teacher's classroom. In addition, the interplay of the four components is not addressed in the model. A specification of the interplay between skill, will, tool and pedagogy-related variables would add substantial complexity to the model. As shown in Fig. 2, the WSTP Model of technology integration can be placed on the STIM framework focusing mostly on the teacher and the teaching side of aspects with overlap into the context as tools are typically related to the context of the environment.

\section{Synthesis of qualitative data (SQD) model}

There are different strategies to prepare pre-service teachers for technology integration in education (Mouza et al. 2014; Tondeur et al. 2020). Therefore Tondeur et al. (2012) and Petko (2012) reviewed empirical studies aiming to synthesize effective strategies. According to the findings of this (qualitative) evidence, twelve key strategies need to be in place while preparing pre-service teachers to use technology. These strategies are presented in the Synthesis of Qualitative Data (SQD) Model (see Fig. 3). This conceptual model is supported by empirical findings of 18 studies (Accuracy). At the same time, the SQD Model

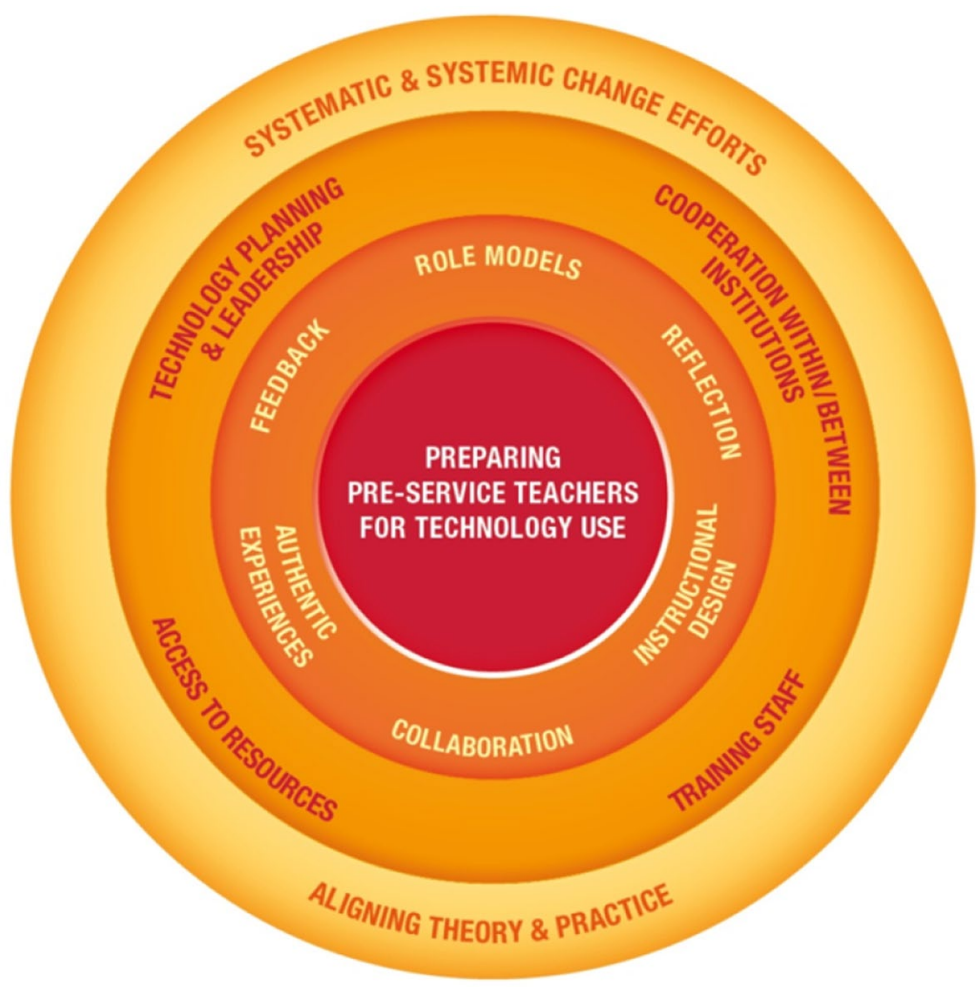

Fig. 3 SQD model to prepare pre-service teachers for technology use (Tondeur et al. 2012; Petko 2012) 
is based on empirical studies from before 2012. Questions still remain on whether new evidence would have changed the themes pictured in the SQD model.

The SQD Model includes three levels of consideration when preparing pre-service teachers for technology use (Tondeur et al. 2012) and Petko (2012). The outer level includes systematic and systemic change efforts, along with aligning theory and practice. The second level considers aspects of the institution, such as technology planning and leadership, training staff, access to resources, or cooperation within and between the institutions. The inner circle includes six micro level strategies: (1) Role models, (2) Reflection, (3) Instructional design, (4) Collaboration, (5) Authentic experiences, and (6) Feedback.

Clearly, the SQD Model reduced the complexity of an interplay of objects and their properties (Simplicity). At the same time, little is known about how the key strategies come together as an integrated approach to prepare teachers for technology integration (Consistency). Therefore, Tondeur et al. (2020) examined relationships among digital competence strategies in pre-service teacher training. More specifically, association rules analysis was used to explore self-organization of the strategies. The results suggest a possible integrated approach. By reducing the complexity in a conceptual model like the SQD Model (Simplicity), it might be difficult to understand the complexity on how each strategy behaves as part of the approach teacher preparation institutions are using to prepare their future teachers.

It seems that the theory embedded within the SQD Model is applicable to a wide range of phenomena with a high degree of generalizability (Scope) and that it can be used across pre-service teacher institutions in other countries. To illustrate, Valtonen et al. (2019) analyzed how well the SQD strategies at the micro level work in the context of Finnish teacher education. The target group consisted of cohorts of 203 last year pre-service teachers. Results indicate that the SQD strategies work well in the Finnish context. The findings also indicate differences between universities in one SQD strategy (Instructional Design). In Belgium, Tondeur et al. (2020) explored the connections between TPACK and the SQD strategies in 19 teacher preparation institutions. The findings clearly demonstrate the importance of the SQD-strategies for enhancing pre-service teachers' TPACK. It seems that the SQD Model aligns with TPACK (Consistency), but it is not clear how it can be aligned with other conceptual models and theoretical models such as Bandura's self-efficacy and Roger's diffusion of innovation. However, most of the SQD studies only focus on the micro level strategies.

Future studies involving the SQD Model could help to analyse practical situations in teacher preparation institutions (Fruitfulness). But the question remains how this conceptual model can be inspiring for practical solutions. SQD can be used as a "thinking tool" for teacher preparation institutions but the strategies that need to be integrated are not described in such a manner that it is clear how to implement them. In this respect, teacher design teams can be a promising approach to integrate the complexity of the SQD strategies mentioned above. A teacher design team can be described as a group of two or more teachers who (re) design curriculum materials together (Handelzalts 2019; Voogt et al. 2016), in this case technology-rich curriculum materials.

\section{Four in Balance Model}

The "Four in Balance" Model reflects a scientifically researched vision for the integration of information and communications technology (ICT), starting from a school improvement point of view (see Fig. 4). This model can provide schools with insight into preconditions for successful educational use of ICT. The underlying theoretical model was developed 


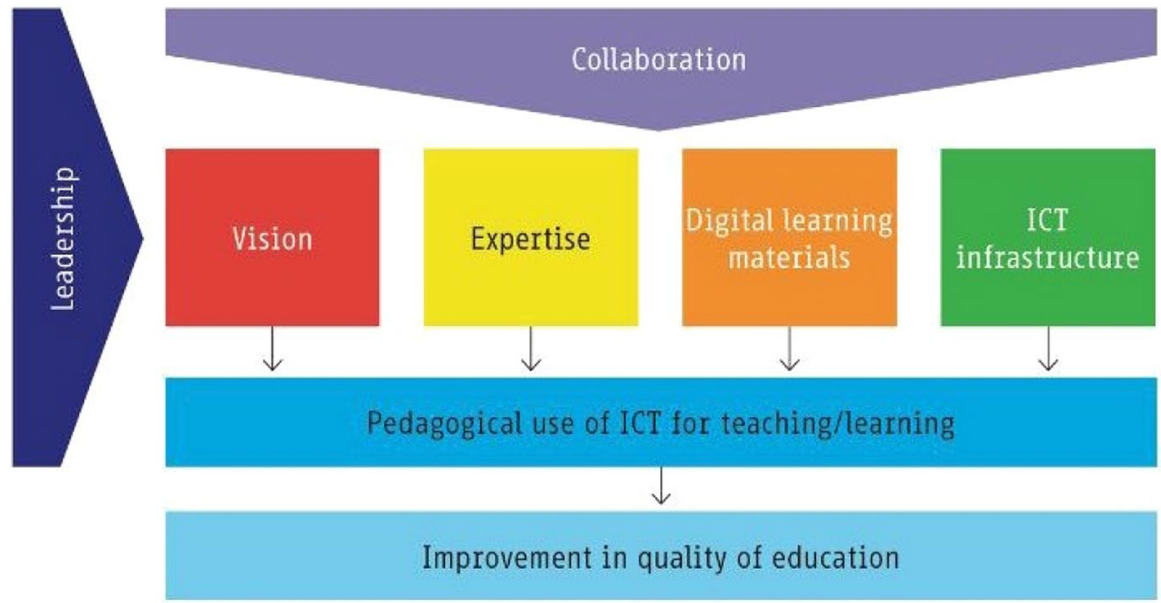

Fig. 4 Four in balance model

from an empirical study (ten Brummelhuis 1995) and tested against international comparative data from several countries (Accuracy), such as France, Germany, Japan, the Netherlands, Switzerland and the United States (Pelgrum and Plomp 1993; Tuijnman and ten Brummelhuis 1992; ten Brummelhuis 1995). In 2001, the results from these studies were summarized and presented for schools by Kennisnet in a comprehensive model entitled "Four in Balance". The central idea behind the Four in Balance Model is that the use of ICT for educational purposes is a matter of a well balanced deployment of these four elements illustrated in a simplified visual (Simplicity): (1) Vision, (2) Knowledge, attitudes and skills (professionalisation), (3) Educational software and content, and (4) ICT infrastructure.

The challenge facing the field of education is to adapt these elements to the learning process for students. A teacher cannot manage this task alone. It demands leadership and the support and cooperation of other professionals. The four elements of this model, together with leadership and cooperation, influence the use of ICT for learning and can be understood as an expansion of other conceptual models such as the TPACK framework (Tondeur et al. 2009) or various technology acceptance models (Consistency).

The principles of the Four in Balance Model can be compared with the principles underlying the Tetris $\odot$ computer game. In this game, the idea is to place geometric figures next to and on top of one another, with points being awarded when zones are completed. The points awarded match the level of the lowest zone. The game is played most efficiently and effectively by keeping the discrepancy between the maximum and minimum levels in the different zones as small as possible. When applying this comparison to the areas important for ICT integration, a balance between vision, knowledge, software and infrastructure is necessary (Kennisnet 2014). The weakest link in the whole ultimately determines the effectiveness of the integration. It is a strength of this model that it specifies the interplay of these factors with the metaphor of "balance". With regard to the Scope of the Four in Balance Model, it clearly focuses on the school leaders and the teachers with little reference to students. In addition, the model is rather nonspecific with regard to the persons responsible for each aspect. The model does not clearly distinguish between system-level, school-level and teacher-level factors. Despite (or maybe because of) this issue, the model 
is generalizable across contexts and over time because the aspects are broad rather than specific, and the model draws on evidence from different contexts (Scope). For example, a vision can vary according to the focus of an education system or schooling context, and infrastructure evolves over time with technological advances. It is this flexibility that enables practical relevance while limiting the ability for scientific empirical validation. However, the scope of the model is also limited as it focuses on teacher and school-related factors and does not account for factors related to students and their backgrounds.

The Four in Balance Model has been practically applied to and validated across a range of schools (Accuracy) in the Netherlands and Flanders (e.g. Gennip et al. 2007; Tondeur et al. 2009). Many schools use this model as a heuristic framework in their ICT policy plan to structure and organize goals and support activities for further integration of ICT (Fruitfulness). Schools in the Netherlands are also supported in using the Four in Balance Model. Until 2017, there has been a series of "Four in Balance Monitor" reports with descriptive data on the progress of the four elements in schools in the Netherlands (https://www.kenni snet.nl/publicaties/vier-in-balans-monitor/). Results provide insight into the current status of elements in the Four in Balance Model and assist school teams to define shared goals. However, the interplay of the four elements has not been scientifically revalidated in these studies. So, the Four in Balance Model appears to have evolved from a conceptual model that was strongly rooted in research to a model that is now exclusively focused on practical application.

\section{Overview of the findings}

In review, the three selected technology integration models were evaluated according to their alignment with the quality criteria identified for conceptual models (see Table 2). While each of the models had some background in empirical research and were aligned with scientific theories and concepts, the empirical support each had a very limited scope that goes hand in hand with a clear orientation towards simplicity. Each model was focused on one central goal and a handful of factors that are essential to achieve this goal (in case of the SQD model: a handful of factors per level). In addition, the goal and the factors were rather loosely defined, often employing everyday language (e.g. "will”, "skill”, "tool") instead of scientific terminology. Each of the models had a graphical representation, but the exact interplay of factors was not precisely specified in these depictions. The practical fruitfulness and applicability of these models are still considered rather high. In sum, all three conceptual models provide simplified blueprints for practical application. Possibly, the reduced complexity, fuzzy wording and the unclear interplay between factors in the graphical representations facilitate practical application. What may be considered as flaws for theoretical models might be strong points for their conceptual counterparts. More details of the cross-case analyses will be described further in the discussion section.

\section{Discussion and conclusion}

This article stresses the distinction between theoretical, conceptual and mental models of technology integration in education. In particular, the distinction between theoretical and conceptual models has not been sufficiently made in the past. When practice-oriented conceptual models are judged using the usual quality criteria for science-oriented theoretical models, they appear to be not sufficiently accurate, not consistent, too limited or too broad 


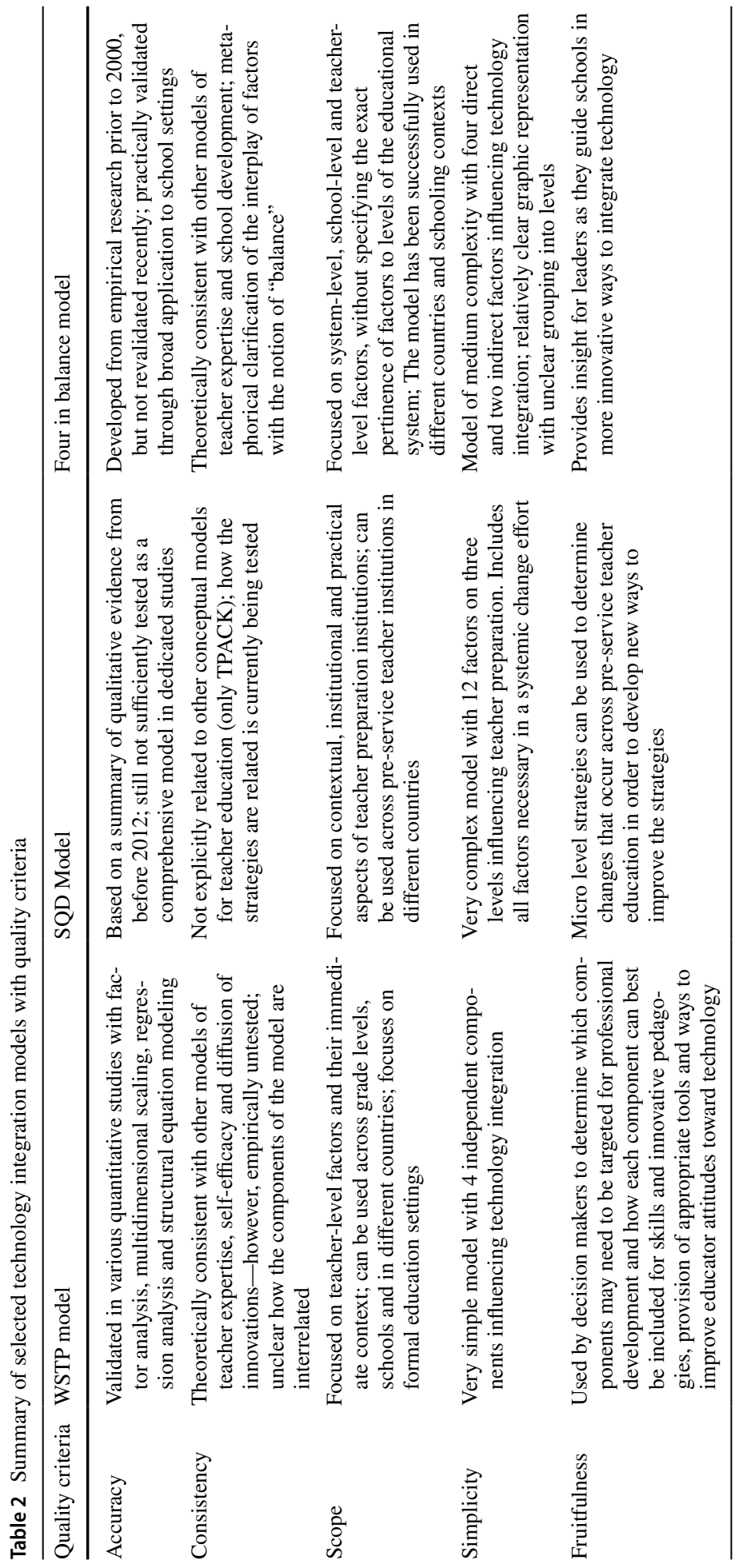


in their scope, too simple or too complex, and not sufficiently fruitful with regard to empirical research and the advancement of theory. When considering these models, research typically calls for conceptual clarifications, better measures or more controlled studies. This has also been the case for research on the TPACK Model (Brantley-Dias and Ertmer 2013; Kimmons 2015; Saubern 2020) and for the SAMR Model (Hamilton et al. 2016), both of which can be considered as conceptual rather than theoretical. As this article illustrates, conceptual models, particularly those focused on technology integration in educational settings, serve a different purpose than purely theoretical models and need to be judged using an adapted set of criteria. Therefore, the main goal of this study was to provide researchers, practitioners and policy makers with a set of criteria that could then be used to assess the quality and scope of different conceptual models in the field of technology integration in education.

Based on the literature (see e.g., Archambault and Barnett 2010; Kimmons 2015; Kuhn 1977), we developed adaptations of the five criteria commonly used to assess the quality of scientific models: (1) Accuracy (empirical validation is essential for conceptual models and they need to be supplemented with practical validation in context), (2) Consistency (to be expanded in relation to other conceptual models and identified epistemologies), (3) Scope (information that facilitates contextual application to take account of the social aspects of educational technology integration, (4) Simplicity (conceptual models should be neither too simple nor too complex and therefore, conceptual models are typically depicted visually which make them likely to be communicated and applied in practice), and (5) Fruitfulness (the conceptual model addresses stakeholders, helps to analyse practical solutions and can be inspiring at the same time). Thus, we took the task of using these five criteria to assess the quality of conceptual technology integration models with the goal of better understanding the relationships between scientific, conceptual and mental models and their application in research settings.

We selected and analysed three technology integration models (i.e., WSTP Model, SQD Model, Four in Balance Model) commonly used by researchers in our field to test the applicability of the quality criteria (for an overview see Table 2). All three models were empirically tested (Accuracy). Both the WSTP Model (Knezek et al. 2000) and the Four in Balance Model (ten Brummelhuis 1995) were first validated with quantitative data using structural equation modelling. In contrast, the SQD Model was derived from a synthesis of qualitative evidence (Tondeur et al. 2012; Petko 2012) and scales were developed to measure the six micro level strategies in a quantitative way (Petko et al. 2018). A second important aspect of the accuracy criteria is the practical validation of the model within a context. Each model was assessed on this aspect and all three, the SQD Model (Baran et al. 2019), the Four in Balance Model and the WSTP Model (Morales 2006; Kennisnet 2014), were applied to a specific educational context when studied.

The quality criterion of Consistency with other models, frameworks and theories can also be applied to the three selected technology integration models. For example, the WSTP Model relates to Bandura's (1977) self-efficacy and Rogers' (1995) diffusion of innovation. While all the selected models have been applied to different contexts, limitations were found. For example, the Four in Balance Model has generic pillars that are applied to different settings across different times. Yet, how each pillar, such as the pedagogical use of ICT for learning, is interpreted or applied can differ leading to mixed interpretations of results. Consistency is about the exploration of relationships between the factors in technology integration models. Both the (components of the) WSTP Model and the SQD Model have been linked to other models such as TPACK but more research is needed to find out how different conceptual frameworks of technology integration can be integrated. 
According to Kimmons et al. (2020), each model speaks its own language (e.g., TPACK, TIM, TAM, SAMR), none tend to recognize other conceptual models nor acknowledge relationships to them.

As stated earlier, conceptual models should also be simple (Graham 2011) and are typically depicted visually which make them likely to be communicated and applied in practice (Simplicity). Each model selected provides a clear graphic representation which also includes the most important factors or constructs used to represent the technology integration focus of the model. Focusing on the most important factors that are relevant to the model makes it easier to apply these models in different contexts, including those at different stages of technology integration, for example, countries with low and high levels of digital access. Strong conceptual models can also be used to compare different contexts (Khine et al. 2017). At the same time, there is a risk of only focusing on the main factors of these conceptual models. Therefore, the use of conceptual models should be the starting point and not the end point of the technology integration process.

Fruitfulness is a quality criterion which focuses on the consequences of applying conceptual models to practical situations. Here, more research is needed to develop guidelines for the applicability of conceptual models in different practical contexts. To deal with these issues, different stakeholders may translate a conceptual model for technology integration in different ways. In contrast to theoretical models, it is not a flaw but rather a feature of conceptual models. In fact, none of the three conceptual models discussed in this article provide clear guidelines about how to apply each model in educational contexts. Nevertheless, the Four in Balance Model has been used to underpin teacher professional development (PD) programs. One such program offered in four Kenyan secondary schools was based on capacity building focusing on the components of the Four in Balance Model: (1) vision building, (2) leadership, (3) collaboration, (4) expertise to use technology, and (5) access to adequate infrastructure (Tondeur et al. 2015). This contrasts with interventions in the Netherlands where decision makers such as school leaders and administrators apply the Four in Balance Model to determine what components need to be targeted for teacher professional learning or infrastructure spending (Kennisnet 2014).

To advance the research and implementation of effective integration of technology in education, it is not only paramount to develop and recognize high quality conceptual models that can be applied to future research and practice but there is also significant value in providing a common framework to compare and combine different models. Thus, a second goal of this article was to compare models for technology integration within the scope of these quality criteria. The identification of quality models of technology integration as well as the recognition of the gaps that are not being addressed in models can guide policymakers and practitioners in their decisions for tools and resources that may be needed to implement effective technology integration. As a result of our collaborative work, the Stage for Technology Integration Models (STIM) framework was developed for the purpose of determining the Scope of existing conceptual models (see Fig. 5). The framework uses the metaphor of a platform or "stage" where different conceptual models can be grouped and compared (cf. Fisser and Phillips 2020) along six distinct areas, including micro-, mesoand macro-factors on the side of either the teacher or the learner. Figure 5 illustrates how some technology integration models focus exclusively on one of these areas, while others provide broader views.

Using the STIM framework helps individuals to visualize the added value of conceptual models and to identify "blind spots" that need to be addressed in future research. One example of a blind spot can be illustrated by looking at Fig. 5 and studying the placement of the selected technology integration models on the STIM framework. None of the 


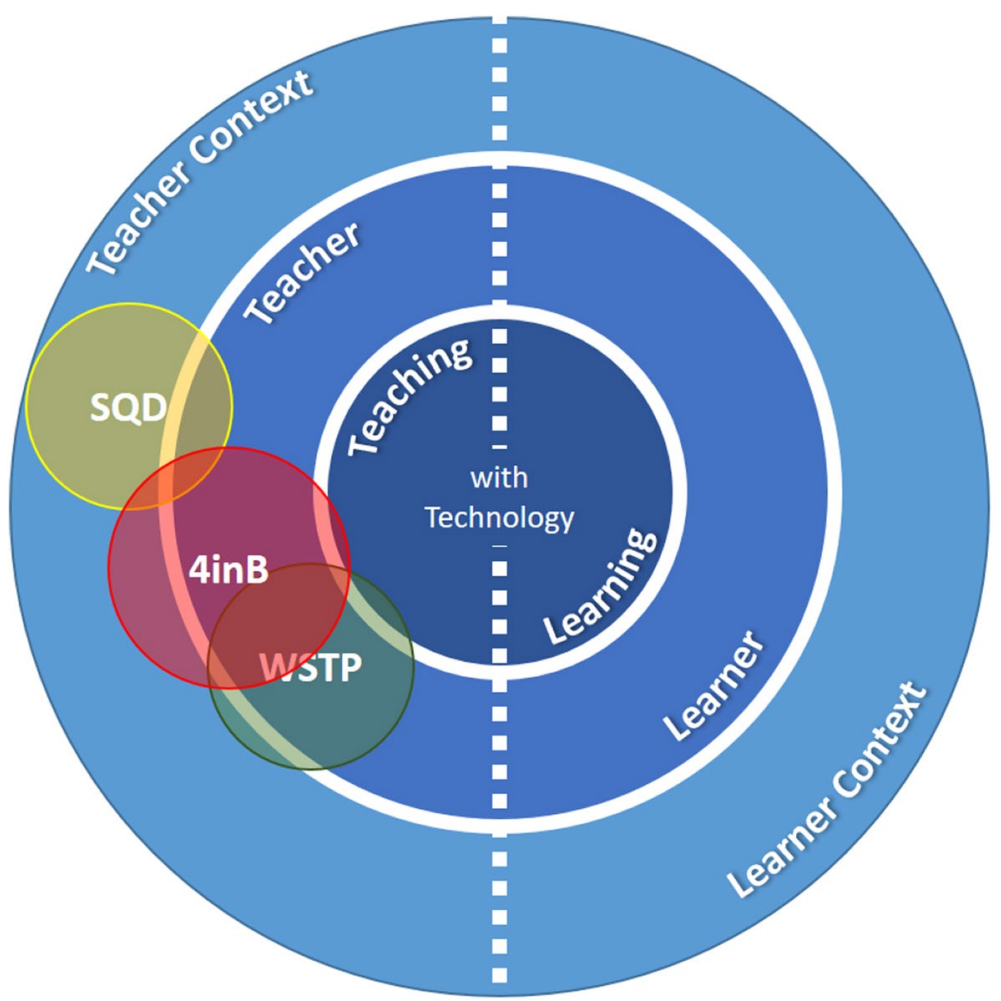

Fig. 5 Conceptual models grouped along the Stage for Technology Integration Models (STIM) framework

featured conceptual models appear to have a strong presence in the areas of Learning, Learners and Learner Contexts, although recent analyses (e.g., Tondeur et al. 2019) have shown that efforts from this bi-annual convening of researchers, practitioners and policy makers at EDUsummIT over the last decade has evolved from an emphasis on technology, to an emphasis on learning. It appears that learning within context, including prediction and assessment thereof, should be an important area of focus and expansion of technology integration models in the future. This brings us to the limitations, recommendations for future research and implications of the study.

It could be considered whether the developed quality criteria for conceptual models could be supplemented by further aspects in order to obtain a more comprehensive picture. For example, a systematic comparison with the five criteria and guiding questions for evaluating technology integration models for student teachers (Kimmons et al. 2020) could help to exploit synergy effects. In addition, other technology integration models could be added to the STIM framework platform (e.g. TIP or TIM), to characterize the blind spots in the conceptualization of the existing models more precisely and to underpin the viability of the STIM framework. Therefore, a systematic approach would be helpful. For example, a database could be created in which different technology integration models are categorized using the quality criteria and STIM framework from the perspective of different actors such as researchers, practitioners and policy makers. This could be helpful to select a model from the perspective of the different actors and possibly even further develop models for 
different contexts. Not least, the involvement of the different actors would also ensure, to include both scientific robustness and application to practice (West et al. 2020).

In conclusion, the article has succeeded in providing researchers, practitioners and policy makers with a set of guidelines that can be used to assess the quality and scope of different conceptual models of technology integration in education. This can ultimately help to advance research and implementation of effective technology integration research in education and to better understand the relationships between scientific, conceptual and mental models and their application in research environments. The STIM framework also contributes to making the added value of conceptual models visible and for identifying "blind spots" that need to be addressed in future research. Therefore, the quality criteria together with the STIM framework enables one to evaluate effective technology integration by aligning the appropriate conceptual model according to purpose, quality and scope. The thoughtful application of technology integration conceptual models will help in identifying gaps in existing research and assist in the practical application of these models in practice.

\section{Compliance with ethical standards}

Conflict of interest The authors do not have any conflicts of interest.

Ethical approval There are no human participants and/or animals involved in this study (concept paper). So no informed consent was needed.

\section{References}

Agyei, D. D., \& Voogt, J. M. (2011). Exploring the potential of the will, skill, tool model in Ghana: Predicting prospective and practicing teachers' use of technology. Computer \& Education, 56, 91-100.

Archambault, L. M., \& Barnett, J. H. (2010). Revisiting technological pedagogical content knowledge: Exploring the TPACK framework. Computers \& Education, 55(4), 1656-1662.

Bandura, A. (1977). Self-efficacy: The exercise of control. New York: W.H. Freeman.

Baran, E., Canbazoglu Bilici, S., Albayrak Sari, A., \& Tondeur, J. (2019). Investigating the impact of teacher education strategies on preservice teachers' TPACK. British Journal of Educational Technology, 50(1), 357-370.

Bhabha, H. K. (1994). The location of culture. New York: Routledge.

Brantley-Dias, L., \& Ertmer, P. A. (2013). Goldilocks and TPACK: Is the construct 'just right? Journal of Research on Technology in Education, 46(2), 103-128.

Bryman, A. (2016). Social research methods (5th ed.). Oxford: Oxford University Press.

Christensen, R., \& Knezek, G. (2001). Instruments for assessing the impact of technology in education. Computers in the Schools, 18(2-3), 5-25. https://doi.org/10.1300/J025v18n02_02.

Cohen, L., Manion, L., \& Morrison, K. (2018). Research methods in education (8th ed.). New York: Routledge.

Collins, A., \& Halverson, R. (2010). The second educational revolution: Rethinking education in the age of technology. Journal of Computer Assisted Learning, 26(1), 18-27.

Coughlin, E., \& Lemke, C. (1999). Professional competency continuum: Professional skills for the digital age classroom. Santa Monica, CA: Milken Exchange.

Creemers, B. P. M. (1994). The effective classroom. London: Cassell.

Davis, F. D. (1989). Perceived usefulness, perceived ease of use, and user acceptance of information technology. MIS Quarterly, 19(2), 319-340. https://doi.org/10.2307/249008.

Earle, R. S. (2002). The integration of instructional technology into public education: Promises and challenges. Educational Technology, 42(1), 5-13.

Ertmer, P. A. (1999). Addressing first-and second-order barriers to change: Strategies for technology integration. Educational Technology Research and Development, 47(4), 47-61. 
Ertmer, P. A., Ottenbreit-Leftwich, A. T., Sadik, O., Sendurur, E., \& Sendurur, P. (2012). Teacher beliefs and technology integration practices: A critical relationship. Computers \& Education, 59(2), 423-435.

Farjon, D., Smits, A., \& Voogt, J. (2019). Technology integration of pre-service teachers explained by attitudes and beliefs, competency, access, and experience. Computers \& Education, 130, 81-93.

Fisser, P., \& Phillips, M. (Eds.). (2020). Learners and learning contexts: New alignments for the digital age. EDUsummIT 2019 - eBook.

Frigg, R., \& Hartmann. (2018). Models in science. In E. N. Zalta (Ed.), The Stanford encyclopedia of philosophy (Summer 2018 Ed.). Retrieved from https://plato.stanford.edu/archives/sum2018/entries/model s-science.

Gennip, H., Smeets, E., \& Marx, T. (2007). Education with ICT 2007 Main research results in second year monitor Four in balance. Retrieved from http://www.ictopschool.net/onderzoek/nieuws/Nieuwsberi cht.2007-10.

Graham, C. R. (2011). Theoretical considerations for understanding technological pedagogical content knowledge (TPACK). Computers \& Education, 57(3), 1953-1960.

Grønfeldt Winther, R. (2015). The structure of scientific theories. Stanford encyclopedia of philosophy. Retrieved from https://plato.stanford.edu/entries/structure-scientific-theories/https://plato.stanford.edu/ entries/structure-scientific-theories/.

Hall, G. E. (1974). The concerns-based adoption model: A developmental conceptualization of the adoption process within educational institutions. Paper presented at the Annual Meeting of the Ameran Educational Research Association (Chicago, Illinois, April 1974).

Hamilton, E. R., Rosenberg, J. M., \& Akcaoglu, M. (2016). The substitution augmentation modification redefinition (SAMR) model: A critical review and suggestions for its use. TechTrends, 60(5), 433-441.

Handelzalts, A. (2019). Collaborative curriculum development in teacher design teams. In J. Pieters (Ed.), Collaborative curriculum design for sustainable innovation and teacher learning (pp. 159-173). Cham: Springer.

Hattie, J. (2009). Visible learning: A synthesis of over 800 meta-analyses relating to achievement. New York: Routledge.

Heikkinen, H. L., de Jong, F. P., \& Vanderlinde, R. (2016). What is (good) practitioner research? Vocations and Learning, 9(1), 1-19.

Inan, F. A., \& Lowther, D. L. (2010). Factors affecting technology integration in K-12 classrooms: A path model. Educational Technology Research and Development, 58(2), 137-154.

Johnson-Laird, P. N. (2013). Mental models and cognitive change. Journal of Cognitive Psychology, 25(2), 131-138. https://doi.org/10.1080/20445911.2012.759935.

Jonassen, D. H. (1995). Operationalizing mental models: Strategies for assessing mental models to support meaningful learning and design-supportive learning environments. In J. L. Schnase \& E. L. Cunnius (Eds.), Proceedings of Cscl 95: The first international conference on computer support for collaborative learning: October 17-20, 1995. Bloomington, Indiana, USA: Indiana University. Retrieved from: https://www.semanticscholar.org/paper/Operationalizing-mental-models\%3A-strategies-for-to-Jonas sen/76c66017275649906b45bac450de55db863250b0.

Kennisnet. (2014). Four in balance monitor. Zoetermeer, The Netherlands: Kennisnet Foundation. Retrieved from https://www.kennisnet.nl/fileadmin/kennisnet/corporate/algemeen/Four_in_balance_monit or_2015.pdf.

Khine, M. S., Ali, N., \& Afari, E. (2017). Exploring relationships among TPACK constructs and ICT achievement among trainee teachers. Education and Information Technologies, 22, 1605-1621. https:// doi.org/10.1007/s10639-016-9507-8.

Kimmons, R. (2015). Examining TPACK's theoretical future. Journal of Technology and Teacher Education, 23(1), 53-77.

Kimmons, R., Graham, C. R., \& West, R. E. (2020). The PICAT model for technology integration in teacher preparation. Contemporary Issues in Technology and Teacher Education, 20(1), 176-198.

Kimmons, R., \& Hall, C. (2018). How useful are our models? Pre-service and practicing teacher evaluations of technology integration models. TechTrends, 62, 29-36. https://doi.org/10.1007/s11528-017-0227-8.

Knezek, G., \& Christensen, R. (2016). Extending the will, skill, tool model of technology integration: Adding pedagogy as a new model construct. Journal of Computing in Higher Education, 28(3), 307-325.

Knezek, G., Christensen, R., Hancock, R., \& Shoho, A. (2000). Toward a structural model of technology integration. In Paper presented to the Annual Hawaii Educational Research Association Conference, Honolulu, Hawaii, February 12, 2000.

Koehler, M., \& Mishra, P. (2009). What is technological pedagogical content knowledge (TPACK)? Contemporary Issues in Technology and Teacher education, 9(1), 60-70. https://doi.org/10.1177/00220 5741319300303. 
Kuhn, T. S. (1977). Objectivity, value judgement, and theory choice. In T. S. Kuhn (Ed.), The essential tension (pp. 320-339). Chicago: University of Chicago Press.

Kulik, C. L. C., \& Kulik, J. A. (1991). Effectiveness of computer-based instruction: An updated analysis. Computers in Human Behavior, 7(1-2), 75-94.

Mayer, R. E. (1989). Models for understanding. Review of Educational Research, 59(1), 43-64.

Mishra, P., \& Koehler, M. J. (2006). Technological pedagogical content knowledge: A framework for teacher knowledge. Teachers College Record, 108(6), 1017-1054. https://doi.org/10.111 1/j.1467-9620.2006.00684.x.

Morales, C. (2006). Cross-cultural validation of the will, skill, tool model of technology integration. University Dissertation Digital.library.unt.edu.

Moreira, G. I. (2000). Mental models, conceptual models and modeling. International Journal of Science Education, 22(1), 1-11. https://doi.org/10.1080/095006900289976.

Mouza, C., Karchmer-Klein, R., Nandakumar, R., Ozden, S. Y., \& Hu, L. (2014). Investigating the impact of an integrated approach to the development of preservice teachers' technological pedagogical content knowledge (TPACK). Computers \& Education, 71, 206-221.

Niederhauser, D. S., \& Lindstrom, D. L. (2018). Instructional technology integration models and frameworks: Diffusion, competencies, attitudes, and dispositions. In J. Voogt, G. Knezek, R. Christensen, \& K.-W. Lai (Eds.), Second handbook of information technology in primary and secondary education (pp. 335-355). Cham, CH: Springer.

Norman, D. A. (1983). Some observations on mental models. In D. Gentner \& A. L. Stevens (Eds.), Mental models (pp. 15-22). New York: Psychology Press.

Pelgrum, W. J., \& Plomp, T. (1993). The worldwide use of computers: A description of main trends. Computers \& Education, 20(4), 323-332.

Petko, D. (2012a). Teachers' pedagogical beliefs and their use of digital media in classrooms: Sharpening the focus of the 'will, skill, tool' model and integrating teachers' constructivists orientations. Computers \& Education, 58(4), 1351-1359.

Petko, D. (2012b). Teachers' pedagogical beliefs and their use of digital media in classrooms: Sharpening the focus of the 'will, skill, tool' model and integrating teachers' constructivist orientations. Computers \& Education, 58(4), 1351-1359.

Petko, D., Prasse, D., \& Cantieni, A. (2018). The interplay of school readiness and teacher readiness for educational technology integration: A structural equation model. Computers in the Schools, 35(1), $1-18$.

Phillips, M. (2015). Models of technology integration. In M. Henderson \& G. Romeo (Eds.), Teaching and digital technologies (pp. 318-331). Port Melbourne: Cambridge University Press.

Puentedura, R. R. (2006). Transformation, technology, and education. Retrieved from http://www.hippa sus.com/resources/tte/

Puentedura, R. R. (2012). The SAMR model: Background and exemplars. Retrieved from http://www. hippasus.com/rrpweblog/archives/2012/08/23/SAMR_BackgroundExemplars.pdf.

Roblyer, M. D., \& Doering, A. H. (2013). Integrating educational technology into teaching (6th ed.). Boston: Pearson.

Rogers, E. M. (1995). Diffusion of innovations (4th ed.). New York: The Free Press of Glencoe.

Rosenberg, J. M., \& Koehler, M. J. (2015). Context and technological pedagogical content knowledge (TPACK): A systematic review. Journal of Research on Technology in Education, 47(3), 186-210.

Saubern, R. (2020). Is TPACK a theory?. In D. Schmidt-Crawford (Ed.), Proceedings of Society for Information Technology \& Teacher Education International Conference (pp. 1958-1964). Online: Association for the Advancement of Computing in Education (AACE). Retrieved May 20, 2020 from https://www.learntechlib.org/primary/p/215977/.

Scheerens, J. (2016). Educational effectiveness and ineffectiveness. A critical review of the knowledge base. Dordrecht: Springer.

Simon, H. A. (2001). Science seeks parsimony, not simplicity: Searching for pattern in phenomena. In A. Zellner, H. A. Keuzenkamp, \& M. McAleer (Eds.), Simplicity, inference and modelling: Keeping it sophisticatedly simple (pp. 32-72). Cambridge: Cambridge University Press.

Sosa, O. G., \& Manzuoli, C. H. (2019). Models for the pedagogical integration of information and communication technologies: A literature review. Ensaio: Avaliação e Polticas Públicas em Educação, 27(102), 129-156. https://doi.org/10.1590/S0104-4036201800270172.

Svetlova, E., \& Dirksen, V. (2014). Models at work-models in decision making. Science in Context, 27(4), 561-577.

ten Brummelhuis, A. C. (1995). Models of educational change: The introduction of computers in Dutch secondary education. Retrieved from https://research.utwente.nl/en/publications/models-of-educa tional-change-the-introduction-of-computers-in-dut. 
Tondeur, J., Coenders, A., van Braak, J., ten Brummelhuis, A., \& Vanderlinde, R. (2009). Using online tools to support technology integration in education. Handbook of research on new media literacy at the K-12 level: Issues and challenges (pp. 389-402). IGI Global: Pennsylvania.

Tondeur, J., De Bruyne, E., Van Den Driessche, M., McKenney, S., \& Zandvliet, D. (2015). The physical placement of classroom technology and its influences on educational practices. Cambridge Journal of Education, 45(4), 537-556.

Tondeur, J., Howard, S., Knezek, G., Voogt, J., Ifenthaler, D., \& Gibson, D., et al (2020). Based implications for policy and practice: Outcomes from EDUsummIT 2019 (Quebec). The 6th International Summit on Information Technology in Education. InEdMedia+ Innovate Learning 2020 Jun 23 (pp. 475-478). Association for the Advancement of Computing in Education (AACE).

Tondeur, J., Scherer, R., Siddiq, F., \& Baran, E. (2020). Enhancing pre-service teachers' technological pedagogical content knowledge (TPACK): A mixed-method study. Educational Technology Research and Development, 68(1), 319-343.

Tondeur, J., van Braak, J., Sang, G., Voogt, J., Fisser, P., \& Ottenbreit-Leftwich, A. (2012). Preparing pre-service teachers to integrate technology in education: A synthesis of qualitative evidence. Computers \& Education, 59(1), 134-144.

Tondeur, J., van Keer, H., van Braak, J., \& Valcke, M. (2008). ICT integration in the classroom: Challenging the potential of a school policy. Computers \& Education, 51(1), 212-223.

Tsai, C.-C., \& Chai, C. S. (2012). The “ third”-order barrier for technology-integration instruction: Implications for teacher education. Australasian Journal of Educational Technology, 28(6), $1057-1060$.

Tuijnman, A. C., \& ten Brummelhuis, A. C. (1992). Determinants of computer use in lower secondary schools in Japan and the United States. Computers \& Education, 19(3), 291-300.

Venkatesh, V., Morris, M. G., Davis, G., \& Davis, F. D. (2003). User acceptance of information technology: Toward a unified view. MIS Quarterly, 27(3), 425-478. https://doi.org/10.2307/3003654.

von Glasersfeld, E., \& Steffe, L. P. (1991). Conceptual models in educational research and practice. The Journal of Educational Thought (JET)/Revue de la Pensée Educative, 25, 91-103.

Voogt, J., Erstad, O., Dede, C., \& Mishra, P. (2013). Challenges to learning and schooling in the digital networked world of the 21st century. Journal of Computer Assisted Learning, 29, 403-413.

Voogt, J. M., Pieters, J. M., \& Handelzalts, A. (2016). Teacher collaboration in curriculum design teams: Effects, mechanisms, and conditions. Educational Research and Evaluation, 22(3-4), 121-140. https://doi.org/10.1080/13803611.2016.1247725.

Welsh, J., Harmes, J. C., \& Winkelman, R. (2011). Florida's technology integration matrix. Principal Leadership, 12, 69-71.

West, R. E., Ertmer, P., \& McKenney, S. (2020). The crucial role of theoretical scholarship for learning design and technology. Education Technology Research Development, 68, 593-600. https://doi. org/10.1007/s11423-020-09770-9.

Publisher's Note Springer Nature remains neutral with regard to jurisdictional claims in published maps and institutional affiliations.

Jo Tondeur is Professor at the Vrije Universiteit Brussel, Belgium. His research is situated within the field of educational innovations. Most of his research focuses on online and blended learning and the integrated use of ICT in pre-service teacher training and compulsory education.

Dominik Petko is Professor of Teaching and Educational Technology at the University of Zurich, where he trains preservice upper secondary school teachers. He has led a number of pioneering projects on educational technology integration in schools and in teacher education in Switzerland.

Rhonda Christensen is a Research Professor in the Learning Technologies Department in the College of Information at the University of North Texas. Her research interests are the impact of technology integration in education, enhancing STEM education in middle schools, simulated learning in preservice education, and mobile learning in education.

Kerstin Drossel ,PD Dr., is a senior researcher at the Institute for Educational Science at Paderborn University, Germany. Her main research interests include school development research, teacher profession(alism), and social disparities. 
Louise Starkey is an Associate Professor in the Faculty of Education at Victoria University of Wellington, New Zealand. Her research and teaching focuses on education in a digital age including the development of professional digital competencies for teachers and educational policy.

Gerald Knezek is Regents Professor of Learning Technologies at the University of North Texas (UNT), USA, and Co-director of the Institute for the Integration of Technology into Teaching and Learning (IITTL). His teaching and research focuses on technology integration, measurement of socio-emotional constructs, STEM education and multidimensional scaling methods.

Denise A. Schmidt-Crawford is Professor and Director of the Center for Technology in Learning and Teaching in the School of Education at Iowa State University. Her research focuses on teachers' development of technological pedagogical content knowledge (TPACK) and her teaching interests include using technology as a tool for innovation in schools and teacher education. 